\title{
Female Body Damage and Decorative Behaviour from the Perspective of Semiotics
}

\author{
Hui TAO ${ }^{1, a}$ and Wen-jiao $\mathrm{LI}^{2, \mathrm{~b},{ }^{*}}$ \\ ${ }^{1}$ Professor, School of Fashion, Wuhan Textile University, Wuhan, China \\ ${ }^{2}$ Graduate Student, School of Fashion, Wuhan Textile University, Wuhan, China \\ a932678733@qq.com, b1124777946@qq.com
}

Keywords: Body damage, Decoration, Symbol, Feminism.

\begin{abstract}
Decoration is one of the important parts in costume, among the various dress cultures of all nations in the world, the phenomenon of body as decoration is the most special one. Making a study on body damage and decorative behaviours of the ethnic minorities, we can learn the original living conditions of people, and understand the aesthetic standards and cultural connotations, and comprehend the gender differences in contemporary ethnic identity. In the view of Gender and Sociology, with the research method of literature analysis, this paper clarified the connotations through the female "pain" decoration actions, and analyzed the role and status of women in ethnic group and modern society.
\end{abstract}

\section{Introduction}

Symbol is a medium to convey information, which means that people use symbols to create culture. Culture doesn't imitate and reproduce things directly, but express with the symbol meaning. "Symbolic thinking and behavior are the most representative feature in human life, and all of human culture depends on these conditions." National dress is undoubtedly a special cultural symbol, and the people in the ethnic groups create a cultural spirit through the abstract symbol, so as to express the inner spiritual needs of the nation.

\section{The Basic Problems of the Feminism and Body Damaged Decoration}

Nowadays, feminism has become one of the most active social trends of thought, which comes from the female liberation movement. Feminism is an academic view, and it is a kind of social theory and political movement. It mainly based on the experience of women, especially the analysis of social relations, and the maintenance of female rights and interests. The themes of feminist inquiry mainly include gender discrimination, physical oppression, patriarchal, stereotype and so on. The so-called body decoration, which means using a variety of methods to directly decorate the human body. Body damaged decoration, which means the methods may damage the external body and the internal function, even the inner soul in a certain degree. In the primitive times and the traditional ethnic groups of the world, the phenomenon of physical damage and adornment is common.

Tattoos are the most common forms of body damaged decoration in ancient times known as "embroidery foot", "embroidery face" and "tattooing". It is a body decoration method that operator uses thorn, needle, knife or other sharp things to stab into the skin, then paints color to form permanent patterns and symbols. Facial tattoo is a type of tattoo. The patterns of the tattoo are mainly the dragon, tiger, snake, frog and other animals or scriptures, geometric patterns, etc. It originated early for the 
religious activities or the decoration customs that primitive people pained in their body.

There is no doubt that the most direct driving force about female decoration on the body is the social standard and qualified, such as etiquette, faith, moral characteristics and aesthetic. Li nationality tattoo is the representative in Chinese original nationalities. Qu-fei Zhou, a Southern Song Dynasty writer, described the Lizu female tattoo in the "Chronicle and Explain about Lingnan" that "the embroidered face, it's a form of Ji in Zhongzhou." "Ji" means girls reach the age of fifteen and will be an adult in ancient China. When girls of Li nation are thirteen years old, they will be made tattoo, the only way to gain a marriage qualification.

In some areas, only the woman embroidered face can become a formal member of the tribe, and can participate in the production activities and social activities of the clan. In some areas, the tattoo show this woman has husband, and in any case cannot remarry. Therefore, the tattoo has a certain constraint on the role of woman and protective means of underage female. This phenomenon widely exists in the patriarchy society. The body decoration as a marker distinguishing women's marital status obviously is to cancel a married woman's free social power. This phenomenon is related to patrilineal family form. It is a marriage means to maintain patriarchy for men.

Tattoo is often used as a special certify that people between the different clans or tribal, distinguish identity and difference tracing of their source. It can make clan members living in different ages get a correct understanding about their ancestors and group. Lizu is animist and they advocate natural, imitate nature. It reflects the view human and nature be made one simple, and the view has certain influence on the Li nationality's tattoo. These abstract patterns often have auspicious and beautiful symbolic meanings. Li women believe thorn needled by Bi Mogen can expel ghost and evil to protect children from harm and illness. The worship of frog of $\mathrm{Li}$ is shown in Fig. 1 and Fig. 2. The frog becomes the symbol of harvest and happiness. And because the frog's breeding ability is very strong, Li also put frog as object to symbolize fertility worship.

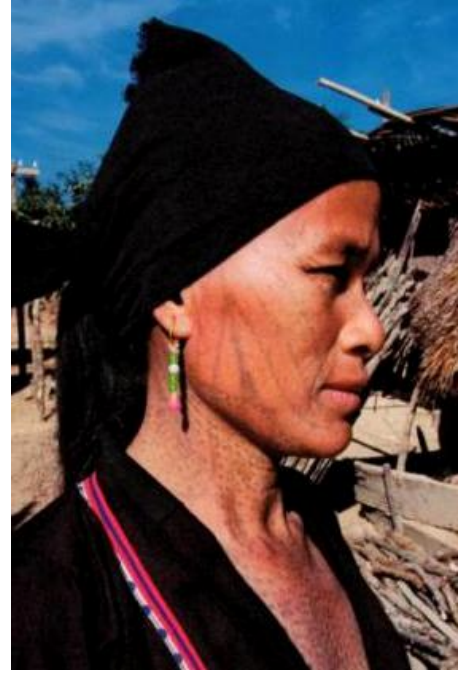

Figure 1. Frog grain in face of Meifu Li

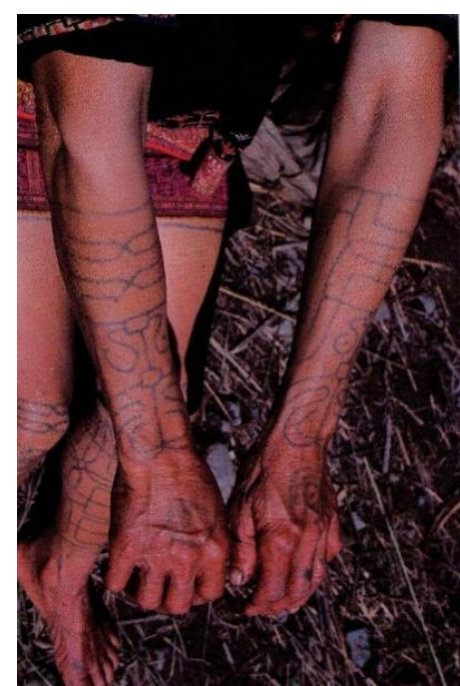

Figure 2. Tattoo in arm of Bendi Li

Perforation, damaged teeth, ringed neck are also common forms of body damaged decoration. "Deang women wore ear column carved ornamentation and coated with black and pink paint. In Yunnan Dehong area, Bulang women decorated with silver 
ear column. "1 The Jinuo men and women wear flowers in the ear hole to indicate adult age and you can also plug with silver ear column and floccules. It is shown in Fig. 3. The Mursi is the most typical nation to perforate in lips. The largest lip plate in the world is shown in Fig. 4. The self-defacing behaviour is said to prevent other tribes to snatch slaveries. Time goes, now it is a marry qualification and relate with the number of dowry and it is a symbol of courage and beauty. This self-mutilation can lead to facial deformation. People endure great physical and psychological pain, but the deformity decoration form is very important in the local, and sometimes they are proud of standing enduring lots of pain.

Destroyed tooth is a sign of adult or married women, or gender oppression. Yi nationality woman in Jinping County, Yunnan stained teeth first time is in adulthood. A Yi Aru girl stained teeth first time is shown in Fig. 5. In Ding County, Guizhou Province, many married Gelao women destroyed the palate large teeth 1-2 pieces before they marry. It's said to prevent women from hurting their husband. Due to the rough operating tool and backward sanitation, many women suffer from various oral diseases and even tooth loss, but people still do that.

Ringed neck custom derives from totem worship. A long neck girl of Ke Yang nationality is shown in Fig. 6. In legend, Burmese Ke Yang's long neck woman's image is in honor of the father of the universe "Long Neck Dragon". But now local people call this custom as a symbol of beauty and wealth. Because collars are metal, when it's high temperature weather, collar absorb much heat easily to burn the skin. And collar is difficult to remove and clean, so it's very unsanitary. The decoration of ringed neck gives women great force and burden also harm women's normal physiological growth, so most of the long-necked women have shorter lifespans.

\section{Patriarchy and Gender Oppression}

Body decoration reflects not only primitive aesthetic and religious consciousness of a nation, but also reflects the views of nature and family, marriage, social organizations and other aspects. From a large number of different minorities literature can we see some similar causes for body decoration. First of all, body decoration is used for a decorating way to express people's pursuit to beauty. Many people live with nature, resulting in a unique aesthetic. Secondly, it comes from the original totem worship or religious beliefs of the nation. People intended to embrace image characteristic drawing in the body or on clothing, and use the power of nature to protect themselves and the nation. In addition, body decoration also shows minority people's pursuit for a better life. Some people want to express their different patterns to peace, courage, good luck, health and other pursuits.

In fact, these various "pain" decoration acts also exist in man. However, male body decoration is to show their own strength and get the female good graces. However, the National Men's body decoration is to show their own strength to get women, while women are more in the patriarchal society consciousness under the passive vilify own decoration form. The reasons for this phenomenon are as follows:

First, the means of production belong to all male not female. With the development of productive forces, through the accumulated experience and knowledge of social division, men mastered the invention and manufacture of tools, and became masters and owners of material wealth. Second, the Divisions between men and women are different. Different modes of social divisions between men and

${ }^{1}$ Yuan Yang, Chinese National Costume Culture, Popular literature and Art Publishing House, 1999. 
women in the production of social status and function also formed a series of value judgment system such as "women are inferior to men". Women are totally restricted in the family and lost their independence, becoming appendage of man. Thirdly, the social consciousness is that males are supposed to be worth more than the other sex. Body decoration practices are established on the rigid feudal hierarchy of a patriarchal society. The notion of ideology has always been an important means of maintaining social order. Although female status has improved over time by comparison, still lower than male.

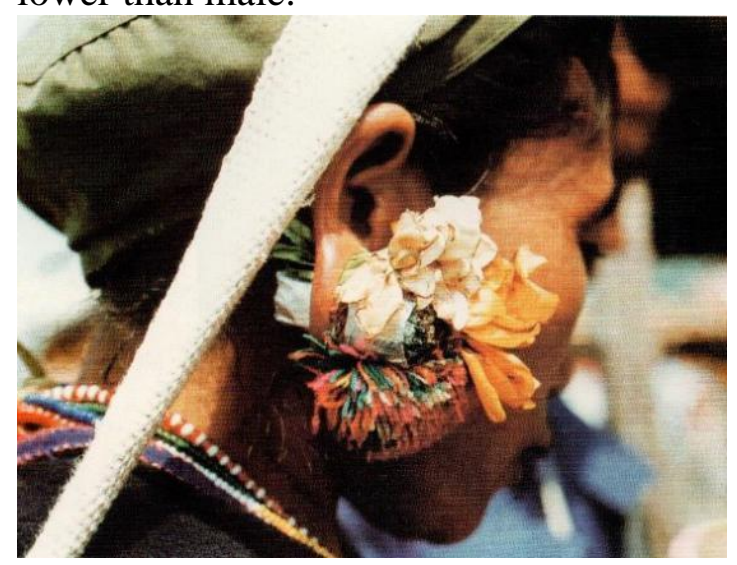

Figure 3. Woman's earrings of Jinuo minority

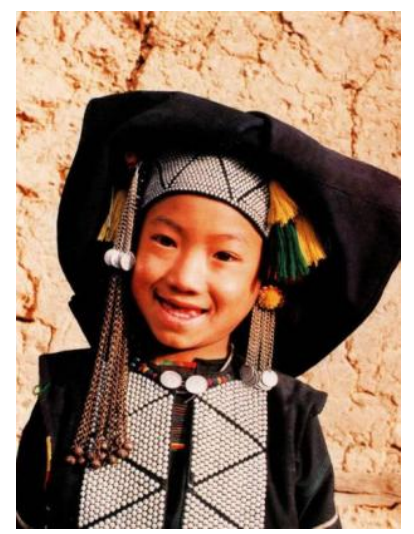

Figure 5. A Yi Aru girl stained teeth first time

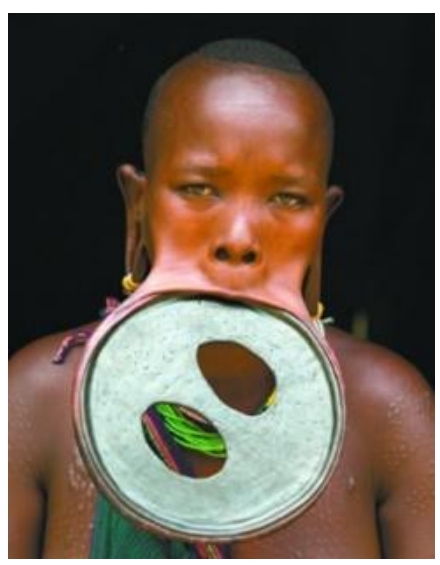

Figure 4. The largest lip plate in the world

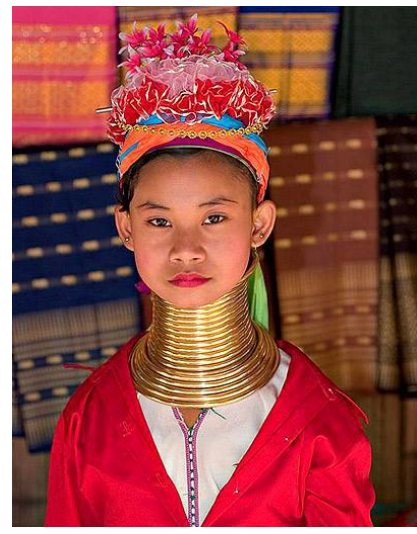

Figure 6. A long neck girl of Ke Yang nationality

Body decoration of ethnic minorities, people's living environment and social life forms are inseparable. Because of the gender nature of inequality in rights, differences of body decoration really exit between men and women. Social gender system directly affects the development of national costumes. This gives us some scientific basis to get comprehensive, in-depth, systematic study of national costumes.

\section{Female Awakening Consciousness}

After the revolution of 1911, the feudal garment system has been abolished, and people's aesthetic standard about garment has been liberated. Female garment began to develop in the direction of individuality and freedom. During the May 4th Movement, the phenomenon's women short hair and wear men's clothes entered an unprecedented climax. For instance, Qiu Jin preferred to wear male student outfit, and Zhang Zhujun, a women activist, often dressed in Western dress and leather shoes. By 
1930s, the government began to intervene the liberation of women and the reform of old customs, so that the Mursi lip, damaged teeth, ringed neck and other mandatory customs have gradually been banned. Women have been liberated from the spiritual to body.

Tattoo, body perforation and other damage decoration methods in the modern environment have been transformed into acceptable states given some new meanings by people, and even they become popular. They attract numerous people in all ages and all occupations with the unique charm. They not only have religious and symbolic significance, but also developed into an exceptive way to show the self-expression, pursuit the individuality, beautify the body for modern. Now that way attract more and more women's attention, thereby they enhance self-confidence, pursuit of individual freedom, gain recognize from public and society. Now, piercing enthusiasts, outlandish costume people uninhibited punk groups and the new feminists have also joined in the team. Now, almost all the younger generation accept tattoo, earring and nose ring and so on, at the same time, gradually affirmed the positive meaning of decorative behaviour on body about national culture and mental performance under the background of new era.

In modern fashion design, feminism is also integrated into it. "Clothing without gender", garment is designed to fuzz and cover female characteristics, instead focus on the nature need of people. In modern society, women who wear suits were generally accepted by society. As one of the representatives of fashion, jeans are an everlasting theme, which symbolize youth and energy. Women's pants became a formal and elegant fashion category. Gender-ambiguous concept is popular in the sensitive fashion. It's the result of not only product development but also prove of women's equality and independence.

\section{Conclusions}

As a symbol of the inner resistance of women, clothing is a language of the external representation of the wearer's outlook on life, aesthetic outlook and personality. Clothing can reflect women's thoughts and accomplishments through clothing, and even the most intimate inner emotional needs. The "self-concept" formation of modern women's clothing is the indispensable part of society, is used to represent the physical self and mental self, and is also a self protection network formed by female self-consciously. Women tend to achieve the purpose of egodefense through clothing showing self-performance and self-recognition, thus promoting the stability and development of the female self-consciousness and personality.

\section{References}

[1] Judith Barrett, Gender Trouble: Subversion of feminism and identity, Translated by Su-feng Song. Shanghai Joint Publishing Company, 2009.

[2] Yuan Yang, Chinese National Costume Culture, Popular literature and Art Publishing House, 1999.

[3] Yun-chuan Che, Research of Ethnic People Costume Ethic, The Journal of Yunnan People College, 2000.

[4] Yang-quan Hu, Analysis of Yunnan Ethnic People Costume Culture Based on Ethnography, Culture Research, 2006. 
[5] Hai-mei Shen, Ethnic Identity Between Men's "Etic" Versus and Women's "Emic" Orientation: Reflections on Social Gender of Ethnic Identity in Contemporary China. Ethno-National Studies Journal, 2004. 